\title{
A Computational Analysis of a Methanol Steam Reformer Using Phase Change Heat Transfer
}

\author{
Hyemin Song ${ }^{1}$, Younghyeon Kim ${ }^{1}$, Dongjin $\mathrm{Yu}^{1}{ }^{1}$, , Byoung Jae $\mathrm{Kim}^{2}{ }^{\circledR}$, Hyunjin $\mathrm{Ji}^{3}$ and \\ Sangseok $\mathrm{Yu}^{2, *}$ \\ 1 Mechanical Engineering, Graduate School, Chungnam National University, 99 Daehangno, Yuseong-gu, \\ Daejeon 34134, Korea; melody_05@naver.com (H.S.); viny9198@naver.com (Y.K.); \\ real-east@hanmail.net (D.Y.) \\ 2 School of Mechanical Engineering, Chungnam National University, 99 Daehangno, Yuseong-gu, \\ Daejeon 34134, Korea; bjkim@cnu.ac.kr \\ 3 Agency for Defense Development, Yuseong P.O.Box 35-44, Daejeon 305-600, Korea; grgnmachine@gmail.com \\ * Correspondence: sangseok@cnu.ac.kr; Tel.: +82-42-821-5646; Fax: +82-42-822-5642
}

Received: 18 May 2020; Accepted: 17 August 2020; Published: 21 August 2020

check for updates

\begin{abstract}
A methanol steam reformer converts methanol and steam into a hydrogen-rich mixture through an endothermic reaction. The methanol reformer is divided into a reaction section and a heat supply section that transfers thermal energy from 200 to $300{ }^{\circ} \mathrm{C}$. This study presents the behavior of the methanol steam reforming reaction using the latent heat of the steam. A numerical analysis was separately conducted for two different regimes assuming constant heat flux conditions. A methanol steam reformer is an annulus structure that has a phase change heat transfer from an outer tube to an inner tube. Different from the steam zone temperature in the tube, the latent heat of steam condensation decreases, and there is a gradual between-wall temperature decrease along the longitudinal direction. Since the latent heat of steam condensation is very sensitive to the requested heat from the reformer, it is necessary to consider a refined design of a methanol reformer to obtain a large enough amount of heat by steam condensation.
\end{abstract}

Keywords: computational analysis; high-pressure methanol steam reformer; phase change heat transfer; high pressure steam condensation; hydrogen production

\section{Introduction}

The exhaust gases from hydrocarbon fuel exacerbate global warming, which has triggered an economy based on hydrogen. Since global warming can be reduced with highly efficient power plants, new types of power plants have also been introduced in the world. Hydrogen energy has the advantage of having a high energy density, low pollutants emission, and fuel flexibility via various sources.

As of yet, the mass production of hydrogen is done by a chemical reaction requiring hydrocarbons. Hydrocarbon-based fuel-producing methods are the steam reforming process, partial oxidation process, and autothermal reforming process. Among them, the steam reforming process is not only economical but also relatively high efficient. The methanol reformer is known for its high energy density per volume, safety, and long-term durability through proper maintenance [1,2]. Various applications are examined such that the methanol reformer is applied to the fuel cell vehicle in the Necar 3 (1997) and Necar 5 (2000). Another application of methanol reformers is a portable fuel cell as a micro-reformer that is used for laptop computers and military robots. Different from the above, the methanol reformer is also used for a high-temperature stationary PEMFC(Proton Exchange Membrane Fuel Cell), which is known to be more tolerable to $\mathrm{CO}$ poisoning [3]. 
The methanol reformer is also applied to an air independent power propulsion system for submarines [4]. Since methanol is safer than hydrogen, it is very attractive to satisfy the requirements of military operations. Prior to methanol reformers, metal hydride was used to store hydrogen for fuel cells. Compared with metal hydride, methanol reformers have longer durability and a larger capacity of energy storage. Since the methanol is reformed for submarines, the operating pressures are very high. Even though the high pressure prevents a highly efficient conversion operation, it is necessary to work the reformer at that pressure to conceal the submarine from an external signature.

Several studies have been done in the field of the methanol steam reforming reaction. Amphlett et al. performed experiments on methanol conversion and reported that methanol conversion increased as the molar number of water vapor increased [5]. Reiyu Chein et al. conducted a numerical study on the steam reforming reaction and identified the mole fractions of methanol, hydrogen, and carbon monoxide in the reforming process [6]. This confirms the validity of numerical analysis for the methanol steam reforming reaction. Additionally, Ataallah et al. developed a three-dimensional model using CFD to study some parameters and features that affect the performance of a methanol steam reformer in a linear reactor with a straight channel [7]. They reported that the performance of the methanol steam reforming reaction at constant inlet mass flow rates and velocities varies with the channel dimensions and operating conditions. Shuji et al. investigated the behavior of catalyst materials, sheet paper containing SiC fibers, catalyst powders, and catalyst pellets, under different space velocities (SV) in the methanol steam reforming reaction [8].

On the other hand, Ji et al. reported on the steam reforming of methanol using phase change heat transfer $[9,10]$. Since the methanol steam reforming temperature ranges from 200 to $300{ }^{\circ} \mathrm{C}$, they had to select an appropriate phase change medium for the temperature range. The phase change medium of their methanol steam reformer was deionized water, and the temperature and pressure of the phase change process were determined by the operating condition of the methanol steam reforming process. This idea is novel, and they experimentally evaluated the performance of the methanol reformer; however, the operating mechanism still needs to be examined. They also show that the high-pressure operation of the methanol steam reforming reaction produces a high concentration of carbon monoxide. They also pointed out that the concentration of carbon monoxide can be significantly reduced with the increasing SM (Steam to Methanol) ratio [11].

In particular, since the reaction mechanism comprises important parameters, the reaction kinetics are widely studied and reported [1-8]. However, most of the methanol steam reforming processes in literature are heated by the combustion of fuel or hot gases. There are scarce reports about the methanol reforming process with phase change heat transfer. Additionally, since the phase change of water around 200 to $300^{\circ} \mathrm{C}$ requires very high vapor pressure, it is very difficult to find an experimental or numerical study of the methanol steam reforming process with phase change heat transfer.

In this study, a computational analysis was performed to investigate the behavior of a high-pressure methanol steam reforming process with phase change heat transfer. The water vapor condensation and the methanol steam reforming reaction take place in a hollow tube. Since the temperature of the phase change medium in the radial direction is varied and in the longitudinal direction as well, the methanol steam reforming reaction is closely linked to those temperature distributions. The computational sections are divided into two different regimes: one for phase change heat transfer and the other for the methanol steam reforming process.

\section{Simulation Model}

The methanol steam reforming process with phase change heat transfer is conducted in annulus tubes that layer two different sizes of tubes in the same center. The methanol and the steam flow into the inner tube, and superheated steam flows into the outer tube. The flow arrangement is a parallel flow. The methanol steam reformer has two compartments, which require two different analysis schemes. One is dominated by a two-phase flow, and the other is dominated by the methanol steam reforming process in porous media. Figure 1 shows the geometric information of the computational 
analysis. There is a methanol steam reforming zone inside of the hollow tube, and heat is supplied from the outer tube to the reaction zone by the phase change of the steam. The flow direction of the reformer zone and phase change zone is parallel. The total height of the tube is $700 \mathrm{~mm}$, and the thickness between the inner shell and outer shell is $2.1 \mathrm{~mm}$. Since heat is transferred from the outer shell to the inner shell, it is observed that the outer surface of the inner shell has condensed vapors on it. The other conditions are summarized in Table 1.
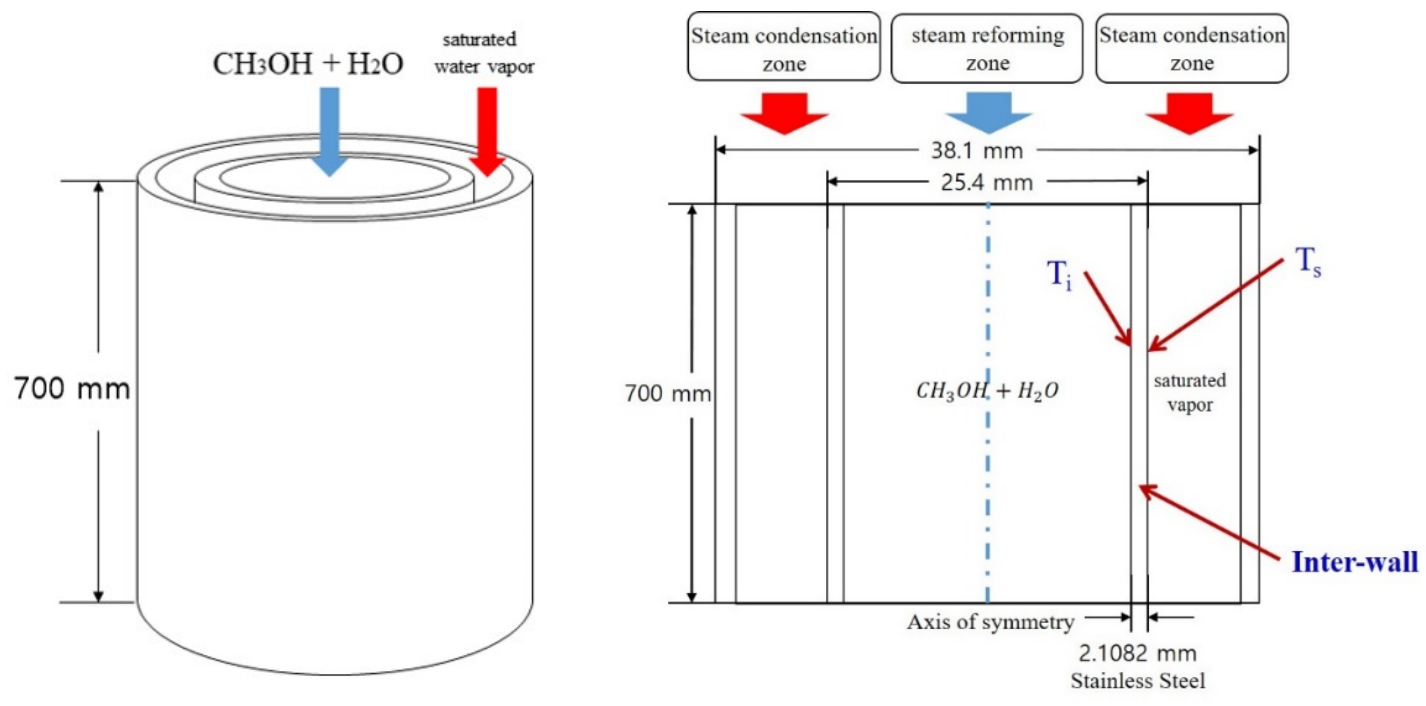

Figure 1. Geometry of methanol steam reformer for numerical computation.

Table 1. Geometric and operating parameters of numerical computation.

\begin{tabular}{cccc}
\hline Parameters & Dimension & Unit & Expression \\
\hline $\mathrm{T} 1$ & 280 & ${ }^{\circ} \mathrm{C}$ & Inlet temperature \\
\hline $\mathrm{Ts}$ & 279.9616 & ${ }^{\circ} \mathrm{C}$ & Saturation temperature \\
\hline $\mathrm{P} 1$ & 64.1646 & bar & $\begin{array}{c}\text { Inlet pressure of steam } \\
\text { condensation zone }\end{array}$ \\
\hline $\mathrm{P} 2$ & 30 & $\mathrm{bar}$ & Inlet pressure of reaction zone \\
\hline $\mathrm{L}$ & 70 & $\mathrm{~mm}$ & Total length \\
\hline $\mathrm{Lt}$ & 2.1082 & $\mathrm{~mm}$ & Tube thickness \\
\hline $\mathrm{r} 1$ & 2.9464 & $\mathrm{~mm}$ & Inlet radius of heat source zone \\
\hline $\mathrm{r} 2$ & 10.5918 & $\mathrm{~mm}$ & Inlet radius of reaction zone \\
\hline $\mathrm{R}$ & 15.6459 & $\mathrm{~mm}$ & Total radius \\
\hline$\rho$ & 8055 & $\mathrm{~kg} / \mathrm{m}^{3}$ & Density of solid tube \\
\hline$C_{p}$ & 480 & $\mathrm{~J} / \mathrm{kgK}$ & Specific heat of solid tube \\
\hline $\mathrm{k}$ & 15.1 & $\mathrm{~W} / \mathrm{mK}$ & Thermal conductivity of solid tube \\
\hline
\end{tabular}

Since the vapor flow goes down by gravity, water vapor condenses on the inner surface of the outer tube. When the temperature of the water vapor meets a vapor saturation state, water droplets cover the outer tube, which act as heat transfer resistance.

\subsection{Reaction Kinetics}

The reaction kinetics of the methanol steam reforming process have been widely investigated. The following three processes are known to be the main reactions of the methanol steam reforming reaction [10-16]. The methanol steam reforming reaction is described by three elementary reactions: 
methanol steam reforming reaction (SR), methanol decomposition (MD), and water gas shift (WGS) reaction.

Methanol steam reforming reaction (SR)

$$
\mathrm{CH}_{3} \mathrm{OH}+\mathrm{H}_{2} \mathrm{O} \rightarrow \mathrm{CO}_{2}+3 \mathrm{H}_{2}
$$

Water gas-shift reaction (WGS)

$$
\mathrm{CO}+\mathrm{H}_{2} \mathrm{O} \rightarrow \mathrm{CO}_{2}+\mathrm{H}_{2}
$$

Methanol decomposition reaction (MD)

$$
\mathrm{CH}_{3} \mathrm{OH} \rightarrow \mathrm{CO}+2 \mathrm{H}_{2}
$$

The Arrhenius equation is applied to calculate the chemical reaction rate. The basic form of the Arrhenius equation is as follows:

$$
\mathrm{k}=A \times \exp \left(-\frac{E_{a}}{R T}\right)
$$

where $E_{a}$ is the activation energy, $A$ is the pre-exponential factor, and $\mathrm{k}$ is the reaction rate constant. The kinetics constants of the methanol steam reforming reaction at 200 to $300{ }^{\circ} \mathrm{C}$ are shown in Table 2 [14-17].

Table 2. Constants of the Arrhenius equation for methanol steam reforming reaction.

\begin{tabular}{cccc}
\hline Reaction Step & $A\left[\mathbf{k m o l} / \mathbf{m}^{3} \mathbf{s}\right]$ & $E_{\boldsymbol{a}}[\mathrm{kJ} / \mathbf{m o l}]$ & Reaction Name \\
\hline $\mathrm{CH}_{3} \mathrm{OH} \rightarrow \mathrm{CO}+2 \mathrm{H}_{2}$ & $1.43 \times 10^{9}$ & $1.22 \times 10^{8}$ & Methanol decomposition reaction \\
\hline $\mathrm{CO}+\mathrm{H}_{2} \mathrm{O} \rightarrow \mathrm{CO}_{2}+\mathrm{H}_{2}$ & $5.115 \times 10^{7}$ & $8.77 \times 10^{7}$ & Water-gas shift reaction \\
\hline $\mathrm{CH}_{3} \mathrm{OH}+\mathrm{H}_{2} \mathrm{O} \rightarrow \mathrm{CO}_{2}+3 \mathrm{H}_{2}$ & $2.002 \times 10^{9}$ & $9.27 \times 10^{7}$ & Steam reforming reaction \\
\hline
\end{tabular}

\subsection{Governing Equations}

The gas mixture of the methanol and steam flows through the inner tube, and the steam reforming reaction is progressed. The governing equations are as follows:

Continuity equation

$$
\nabla \cdot(\rho v)=0
$$

Momentum equation

$$
\nabla \cdot(\rho v v)=-\nabla \rho+\nabla \cdot(\bar{\tau})+\rho g
$$

Energy balance equation

$$
\begin{gathered}
\nabla \cdot(v(\rho E+p))=\nabla \cdot K_{e f f} \nabla T-\sum h_{i} J_{j}+S_{h} \\
E=h-\frac{p}{\rho}+\frac{v^{2}}{2}, h=\sum_{i} Y_{i} h_{i} \\
h_{j}=\int_{T_{\text {ref }}}^{T} C_{p} d T, \overline{J_{j}}=-\left(r D_{j, m}+\frac{\mu_{t}}{S c_{t}}\right) \nabla Y_{j}, k_{e f f}=k+\frac{c_{p} \mu_{t}}{P r_{t}}, S_{h}=-\sigma_{j} \frac{h_{j}^{0}}{M_{i}} R_{j} .
\end{gathered}
$$

The reforming zone is filled with a catalyst. The reaction zone is set up to be porous media, and the catalytic reaction on the surface of the pellet is simulated by chemical kinetics. It is assumed that the porous media is charged homogenously, and the flow is laminar. Darcy's law is used to determine the internal velocity.

$$
\Delta p=C_{2} \frac{1}{2} \rho \Delta n v^{2}+\frac{1}{\alpha} \Delta n v \mu
$$


Darcy's law is represented by the sum of the inertial resistance and the viscous resistance. In addition, the porosity should be set and expressed as $r$ in the following equation.

$$
k_{e f f}=\gamma k_{f}+(1-\gamma) k_{s}
$$

The porosity $(r)$ is the ratio of the fluid volume to the total volume. The effective heat transfer coefficient $\left(k_{e f f}\right)$ is determined by the sum of $k_{f}$, the heat transfer coefficient in the fluid zone, and $k_{s}$, the heat transfer coefficient in the solid zone. On the other hand, saturated steam flows into the empty space in the outer tube, and the condensation condition is determined by the steam pressure and temperature. When the steam is induced, the pressure is set as $64.16 \mathrm{bar}$ and the saturation temperature is set to $279.96{ }^{\circ} \mathrm{C}(553.11 \mathrm{~K})$. When the endothermic reaction takes place in the reaction zone, the heat absorption results in the condensation of the steam. The vapor condensation is calculated by the Eulerian Lee model [14]. The liquid-vapor mass transfer (evaporation and condensation) is governed by the vapor transport equation.

$$
\frac{\partial}{\partial t}\left(\alpha_{v} \rho_{v}\right)+\nabla \cdot\left(\alpha_{v} \rho_{v} \overrightarrow{v_{v}}\right)=\dot{m}_{l v}-\dot{m}_{v l}
$$

Here, $\dot{m}_{l v}$ and $\dot{m}_{v l}$ are the rates of mass transfer due to evaporation and condensation, respectively. In the evaporation-condensation problem, mass transfer from the liquid to vapor is a positive mass transfer, and the units of Equation (11) are in $\mathrm{kg} / \mathrm{s} / \mathrm{m}^{3}$. The mass transfer rate on the right hand side of Equation (11) is defined as follows:

$$
\begin{gathered}
\text { If } T_{l}>T_{\text {sat }}(\text { evaporation }), \dot{m}_{l v}=\text { coef } f \times \alpha_{l} \rho_{l} \frac{\left(T_{l}-T_{\text {sat }}\right)}{T_{\text {sat }}} \\
\text { If } T_{v}<T_{\text {sat }} \text { (condensation), } \dot{m}_{v l}=\operatorname{coef} f \times \alpha_{v} \rho_{v} \frac{\left(T_{\text {sat }}-T_{v}\right)}{T_{\text {sat }}} .
\end{gathered}
$$

Here, $\alpha$ and $\rho$ are the phase volume fraction and density, respectively. coeff is a coefficient that must be tuned finely and can be interpreted as a relaxation time. The volume fractions represent the space occupied by each phase. The volume $V_{c}$ of phase $\mathrm{q}$ is defined as follows.

$$
\begin{gathered}
V_{q}=\int \alpha_{q} d V \\
\sum_{q=1}^{n} \alpha_{q}=1 .
\end{gathered}
$$

The effective density of $q$ is expressed as follows.

$$
\hat{\rho}_{q}=\alpha_{q} \rho_{q} .
$$

In the above expression, $\rho_{q}$ is the physical density of phase $q$. In addition, the governing equation on $q$ is as follows.

Continuity equation

$$
\frac{\partial}{\partial t}\left(\alpha_{q} \rho_{q}\right)+\nabla \cdot\left(\alpha_{q} \rho_{q} \overrightarrow{v_{q}}\right)=\sum_{p=1}^{n}\left(\dot{m}_{p q}-\dot{m}_{q p}\right)+S_{q}
$$

Here, $v_{q}$ is the velocity of phase $q, \dot{m}_{p q}$ characterizes the mass transfer from the $p$ th to $q$ th phase, and $\dot{m}_{q p}$ characterizes the mass transfer from phase $q$ to phase $p$.

The momentum balance equation for phase $q$ yields

$$
\frac{\partial}{\partial t}\left(\alpha_{q} \rho_{q} \vec{v}_{q}\right)+\nabla \cdot\left(\alpha_{q} \rho_{q} \vec{v}_{q} v_{q}\right)=-\alpha_{q} \nabla p+\nabla \cdot \tau_{q}+\alpha_{q} \rho_{q} \vec{g}+\sum_{p=1}^{n}\left(\vec{R}_{p q}+\dot{m}_{p q} \vec{v}_{p q}-\dot{m}_{q p} \vec{v}_{q p}\right)+\vec{F}_{q}+\vec{F}_{l i f t, q}+\vec{F}_{v m, q} .
$$

This is the momentum balance equation for phase $q$ where $\tau_{q}$ is the $q$ th phase stress-strain tensor. 


$$
\tau_{q}=\alpha_{q} \mu_{q}\left(\nabla \vec{v}_{q}+\nabla \vec{v}_{q}^{T}\right)+\alpha_{q}\left(\lambda_{q}-\frac{2}{3} \mu_{q}\right) \nabla \cdot \vec{v}_{q} I
$$

Here, $\tau_{q}$ and $\mu_{q}$ are the shear and bulk viscosity of phase $q ; \vec{F}_{q}$ is an external body force; $\vec{F}_{l i f t, q}$ is a lift force; $\vec{F}_{v m, q}$ is a virtual mass force; $\vec{R}_{p q}$ is an interaction force between the phases, and $p$ is the pressure shared by all the phases.

Lift forces act on a particle mainly due to velocity gradients in the primary phase flow field. The lift force will be more significant for larger particles, but the ANSYS Fluent ${ }^{\circledR}$ model assumes that the particle diameter is much smaller than the inter-particle spacing [14]. Thus, the inclusion of lift forces is not appropriate for closely packed particles or for very small particles. The lift force acting on a secondary phase $\mathrm{p}$ in a primary phase $\mathrm{q}$ can be calculated by the formula below.

$$
\vec{F}_{l i f t}=-C_{l} \rho_{q} \alpha_{p}\left(\vec{v}_{q}-\vec{v}_{p}\right) \times\left(\nabla \times \vec{v}_{q}\right)
$$

The inertia of the primary-phase mass encountered by the accelerating particles (or droplets or bubbles) exerts a "virtual mass force" on the particles. The virtual mass force is as follows.

$$
\vec{F}_{v m}=C_{v m} \alpha_{p} \rho_{q}\left(\frac{d_{q} \vec{v}_{q}}{d t}-\frac{d_{p} \vec{v}_{p}}{d t}\right)
$$

$\vec{R}_{p q}$ depends on the fiction, pressure, cohesion, and other effects. $\vec{v}_{p q}$ is the interphase velocity, which is defined as follow. If $\dot{m}_{p q}>0$, then $\vec{v}_{p q}=\vec{v}_{p}$, If $\dot{m}_{p q}<0$, then $\vec{v}_{p q}=\vec{v}_{q}$. Likewise, If $\dot{m}_{q p}>$ 0 then $\vec{v}_{p q}=\vec{v}_{q}$, If $\dot{m}_{q p}<0$ then $\vec{v}_{p q}=\vec{v}_{p}$.

\subsection{Computational Methods and Boundary Conditions}

Meshes are shown in Figure 2. The solver is a pressure-based solver, and a transient analysis was conducted. Additionally, axisymmetric computation was used to facilitate the analysis. The condensation/evaporation model is a Eulerian Lee Model which is provided by ANSYS Fluent ${ }^{\circledR}$. At the wall of the outer tube, the adiabatic condition was applied for the heat transfer, and wall conditions were also selected for the momentum. Another adiabatic condition was set up along the symmetric axis. At the inter-wall between the inner tube and outer tube, a boundary condition was set up.



Figure 2. Meshes and domains for computational analysis.

Generally, the inner tube and outer tubes were set up to be two computational domains. However, because it is very difficult to solve the computation of two different physics simultaneously 
in the commercial software ANSYS fluent ${ }^{\circledR}$, this study separated the computation of those physics one by one by selecting coupling boundary conditions.

The Eulerian Lee model requires fine tuning of the parameters, which is known as a frequency factor [18]. The frequency factor affects the condensation or evaporation mass transfer rate that is empirically determined. Accordingly, it is necessary to tune the frequency factor so that the phase change mass transfer rate is reasonably determined. This is a clue to tune the model so that the proper heat flux determines the heat transfer coefficients and surface temperature.

At first, the constant heat flux conditions were the boundary condition of the inner tube side of the inter-wall. The first domain was the steam reforming zone, and the second domain was the solid tube. When the methanol steam reforming reaction progresses through the inner tube, it is assumed that a constant heat flux is absorbed from the steam condensation zone.

When the constant heat flux is acting on the surface of the inner wall, the inter-wall temperatures is $T_{s}$ which is the surface temperature of the phase change zone, and the inner wall temperature is $T_{i}$ which is the surface temperature of the steam reforming zone. Those notations are also found in Figure 1. The constant heat flux boundary conditions were set up to be 1, 2.5, and $5 \mathrm{~kW}$. Equation (22) explains the heat transfer correlation with the induction of the constant heat flux from the wall. $T_{s}, T_{i}$, and $h$ are unknowns, and $h$ is a function of $T_{s}$. The methanol and steam mixture temperature through the inner tube and steam temperature through the outer tube were varied in the longitudinal direction. The heat transfer rate should be calculated by the log mean temperature difference (LMTD). It is assumed that the steam is not fully condensed throughout the outer tube. Then, the steam temperature of the outer tube should be maintained. Then, the heat transfer rate is explained as follows:

$$
\begin{gathered}
q_{w}=\frac{2 \pi L k\left(T_{s}-T_{i}\right)}{\ln \left(\frac{r_{o}}{r_{i}}\right)}=\bar{h} A_{s} \Delta T_{l m}\left(T_{\infty}=\text { constant }\right) \\
\Delta T_{l m}=\frac{\Delta T_{o}-\Delta T_{i}}{\ln \left(\frac{\Delta T_{o}}{\Delta T_{i}}\right)} \\
\frac{\Delta T_{o}}{\Delta T_{i}}=\frac{T_{\text {steam }}-T_{s, o}}{T_{\text {steam }}-T_{s, i}}=\exp \left(-\frac{P L}{\dot{m} c_{p}} \bar{h}\right)\left(T_{\text {steam }}=\text { constant }\right) .
\end{gathered}
$$

The convection heat transfer coefficient on the wall of a circular tube is calculated by the following Equation [19].

$$
\bar{h}=\frac{R e_{\delta} \mu_{l} h_{f g}}{4 L\left(T_{\text {sat }}-T_{s}\right)}
$$

where,

$$
\operatorname{Re}_{\delta}=\left[\frac{3.70 k_{l} L\left(T_{s a t}-T_{s}\right)}{\mu_{l} h_{f g}\left(\frac{v_{l}^{2}}{g}\right)^{\frac{1}{3}}}+4.8\right]^{0.82}\left(30 \leq \operatorname{Re}_{\delta} \leq 1800\right) .
$$

All liquid property should be obtained from the film temperature $T_{f}=\left(T_{s a t}+T_{s}\right) / 2$, and $h_{f g}$ should be obtained from $T_{\text {sat }} . T_{S}$ in Equation (25) is calculated by the arithmetic average of $T_{S}$ in between the inlet and outlet. Since the average heat transfer coefficient $\bar{h}_{L}$ is calculated by Equations (22) and (25), a new temperature $T_{S}$ is updated by iteration.

The temperatures in Table 3 were used to determine the frequency factors of each heat flux case. Then, the frequency factor was fixed, and the phase change phenomena were analyzed.

Table 3. Inner wall temperature and inter-wall temperature in terms of constant heat flux conditions.

\begin{tabular}{ccc}
\hline Heat Rate $[\mathbf{k W}]$ & $\boldsymbol{T}_{\boldsymbol{s}}[\mathrm{K}]$ & $\boldsymbol{T}_{\boldsymbol{i}}[\mathrm{K}]$ \\
\hline 1 & 545.17 & 542.54 \\
2.5 & 534.79 & 527.96 \\
5 & 514.39 & 500.73 \\
\hline
\end{tabular}




\section{Simulation Results and Discussion}

\subsection{Phase Change Trends with Surface Heat Absorption}

As the heat fluxes were increased, the steam temperature decreased in the radial direction. Condensation was also observed on the surface. Figure 3 shows the steam temperature profile and liquid volume fraction profile in the outer tube. As expected, the near-wall temperature is about $7 \mathrm{~K}$ lower for the $1 \mathrm{~kW}$ heat absorption. Then, the wall temperature further decreased with a higher heat absorption rate. Near the inter-wall, the steam temperature slope was dramatically decreased due to heat absorption. Then, the steam temperature in the phase change zone rose rapidly to $280{ }^{\circ} \mathrm{C}$, which is the inlet temperature of the steam. Another aspect was the temperature profile in the radial direction. As shown in Figure 3, the near-wall temperature gradient was quite large, and a very thin boundary layer was observed regardless of the absorbed heat. This is because the condensed liquid increases the thermal resistance of the heat transfer. Accordingly, the outer zone from the temperature boundary layer maintained its temperature at the phase change condition.



Figure 3. Vapor temperature and water volume fraction along flow direction (three different heat fluxes as well boundary conditions).

As the heat absorption increased, the liquid volume fraction near the wall is almost 1.0, which implies that the surface is covered with a thin liquid film. The gravity force made the liquid volume fraction boundary layer become thicker along the channel. As steam flows into the outer tube, the liquid volume fraction steeply increased. The more heat is absorbed, the earlier the saturated water is observed through the tube. Then, the liquid volume fraction grew near the inter-wall along the longitudinal direction. It was also shown that most of the area in the outer tube was occupied by saturated steam.

The thermal boundary layer thickness was defined as 0.999 of the free stream temperature, and the liquid volume fraction was defined as 0.999 of the saturated vapor. The results are shown in Figure 4 . The thickness of the temperature boundary layer was thinner than the thickness of the liquid volume fraction boundary layer. It shows that the mixture of steam and liquid water stayed on the liquid boundary layer. As observed, the concentration boundary layer is thicker for all the heat absorption rates, and the thickness increased linearly. The thickness difference between the boundary layer is large for the $1 \mathrm{~kW}$ heat absorption condition. As the heat absorption rate was increased, the thickness difference between the two boundary layers changed little.

The radial temperature profile is shown in Figure 5. The linear increase zone is the solid inter-wall, and a steep temperature increase was observed from the surface of the inter-wall to the steam zone. The overall steam temperature in the radial direction was mainly constant at the saturated condition. Another observation was the gradual temperature down along the longitudinal direction. Even though the temperature of the steam was maintained, the wall temperature decreased with a higher heat flux. One interesting feature is the steam temperature. The steam temperature was maintained over 
the various heat flux conditions, while the wall temperature dramatically changed with the higher heat flux.

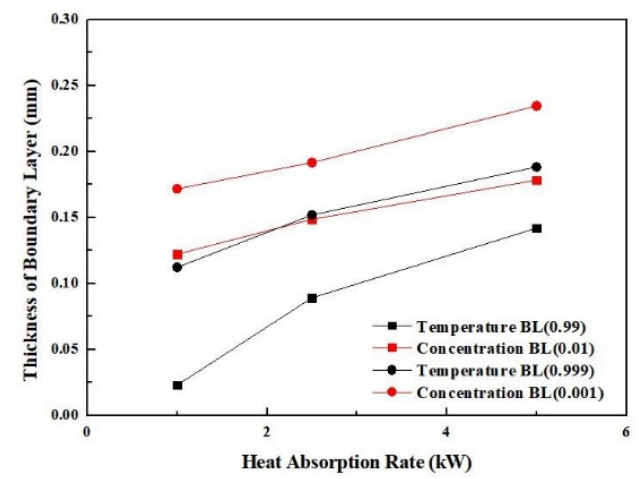

Figure 4. Temperature and liquid volume fraction boundary layer thickness at the exit of the outer tube for the three different heat absorption rates.

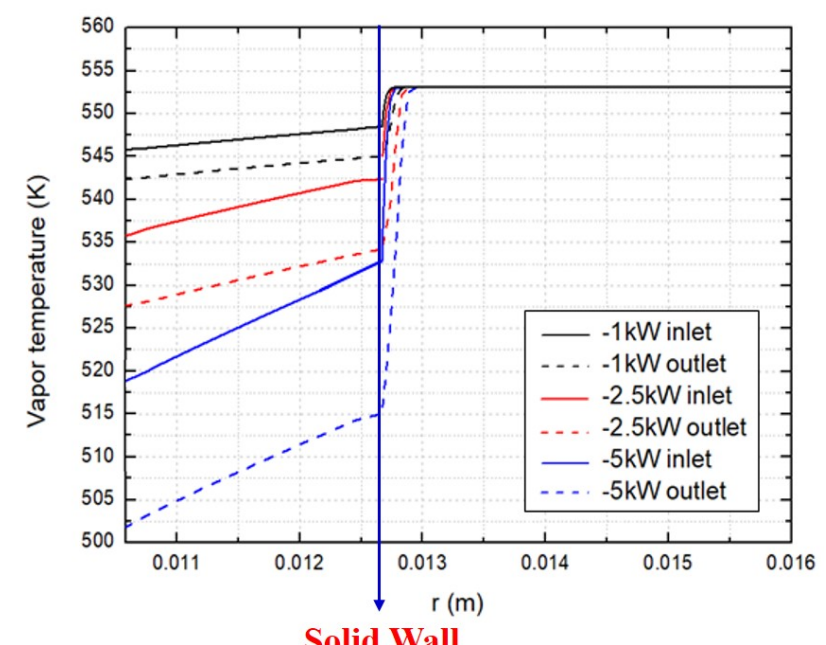

Solid Wall

Figure 5. Evolution of radial temperature profile in terms of the heat fluxes.

The water volume fraction of the outer tube rapidly increased right after inducing the steam, and the water volume fraction was then 1 at the exit. Figure 6 shows the water volume fraction at the inlet and exit. As observed, the water volume fraction at the inlet is steeper with a higher heat absorption rate, and the water volume fraction at the exit is thicker with a higher amount of heat flux.

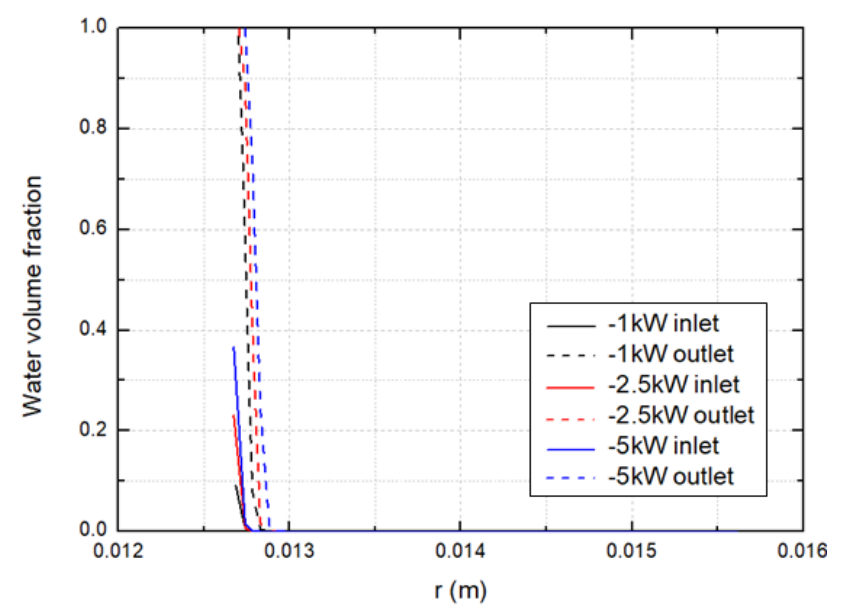

Figure 6. Water volume fraction near the wall in terms of the heat flux. 
The overall liquid fraction of the saturated steam along the outer tube is determined by the integration of the liquid mass over the space. Thermodynamically, the quality is the ratio of the steam mass to the total mass and is calculated as follows.

$$
\begin{gathered}
x=\frac{m_{g}}{m_{g}+m_{f}} \\
x_{w}=1-x=\frac{m_{f}}{m_{g}+m_{f}}
\end{gathered}
$$

Here, $x$ is the quality; $x_{f}$ is the water mass ratio; $m_{g}$ is the mass of them steam, and $m_{f}$ is the mass of the water. Figure 7 shows the total mass ratio of condensed water in the outer tube. As shown, the ratio of condensed water is proportional to the heat flux to the steam reforming process. The ratios of the water mass to the total mass for each heat flux condition were $26.38 \%, 33.95 \%$, and $40.10 \%$. Accordingly, the volume of the liquid is relatively small, and the mass of the steam is not negligible.

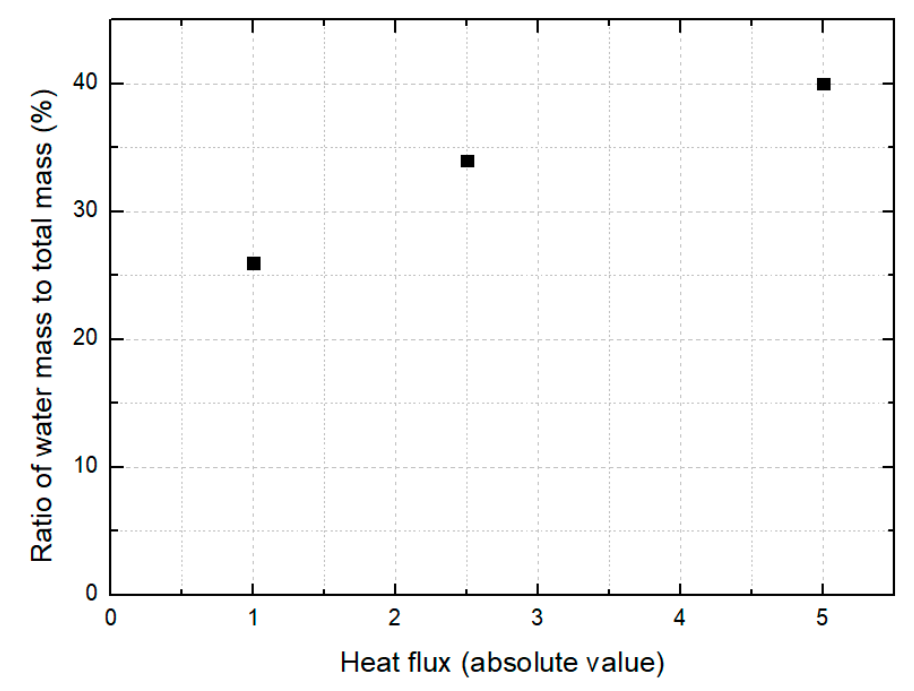

Figure 7. Ratio of water mass to total mass over three different heat fluxes.

The heat absorption from the phase changing steam results in a temperature change on the inter-wall surface. The surface temperature of the inner tube $\left(T_{i}\right)$ is captured in Figure 8. As shown, the surface temperature non-linearly decreased, and the initial temperature was lower than the steam methanol inlet temperature. One reason is from heat transfer through the solid wall. The solid wall is acting as thermal resistance to the heat transfer. Another reason is the condensation of the steam from the inlet. As shown in Figure 4, a significant temperature drop is observed at the near inlet of the phase change zone. The temperature drop results in a lower temperature of the solid surface $\left(T_{i}\right)$ at the inlet of the methanol steam reforming zone.



Figure 8. Inner wall temperature profile along the channel with $2.5 \mathrm{~kW}$ heat flux. 


\subsection{Physical Behavior in the Methanol Steam Reforming Reaction}

The temperature profile through the inner tube was determined by the boundary conditions and reaction characteristics. The temperature trends were observed at the $2.5 \mathrm{~kW}$ heat flux boundary conditions. Due to the presence of the porous methanol steam reforming catalyst, the temperature profile in the radial direction is almost flat. The longitudinal temperature profile is determined by the temperature profile in Figure 8 and the symmetry condition. Figure 9 shows the temperature profile of the chemical reaction zone. The gas inlet temperature was $553 \mathrm{~K}$, which was a higher temperature than the wall temperature. As observed, the initial gas temperature rapidly dropped due to the temperature difference between the gas temperature and the wall temperature. After the first hill from the higher temperature to the lower temperature, the temperature profiles can be seen in Figure 8 . Then, the methanol steam mixture temperature is similar to the wall temperature. The mixture temperature was $553 \mathrm{~K}$ at maximum and $527 \mathrm{~K}$ at minimum.

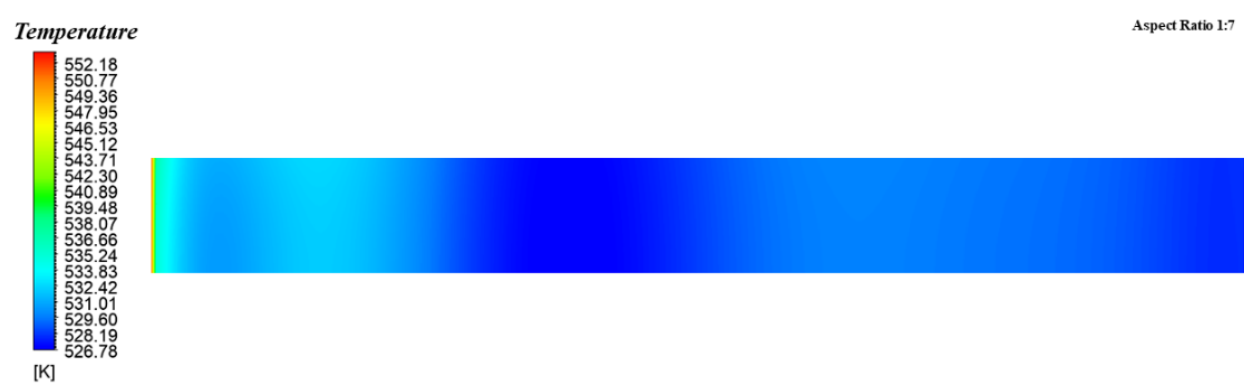

Figure 9. Temperature of chemical reaction zone (2.5 kW heat flux).

Methanol steam reforming reaction consists of three reaction mechanism: steam reforming reaction, water gas shift reaction, and methanol decomposition reaction. Those three reactions are traced in Figure 10. As observed, the order of the steam reforming reaction is almost $10^{3}$ times greater than the other two reactions. Accordingly, the products of the reforming reaction will be mainly $\mathrm{H}_{2}$, $\mathrm{CO}_{2}$, and $\mathrm{H}_{2} \mathrm{O}$. Another aspect is that the reaction rates decay along the channel. Initially, the reaction rate of the steam reforming reaction was quite high and steeply decreased along the channel. It was observed that the wall temperature profile affects the decay of the methanol decomposition rate. However, the methanol steam reforming reaction rate looks less affected by the wall temperature profile. Instead, the concentration of methanol has a more significant effect on the methanol steam reforming reaction.

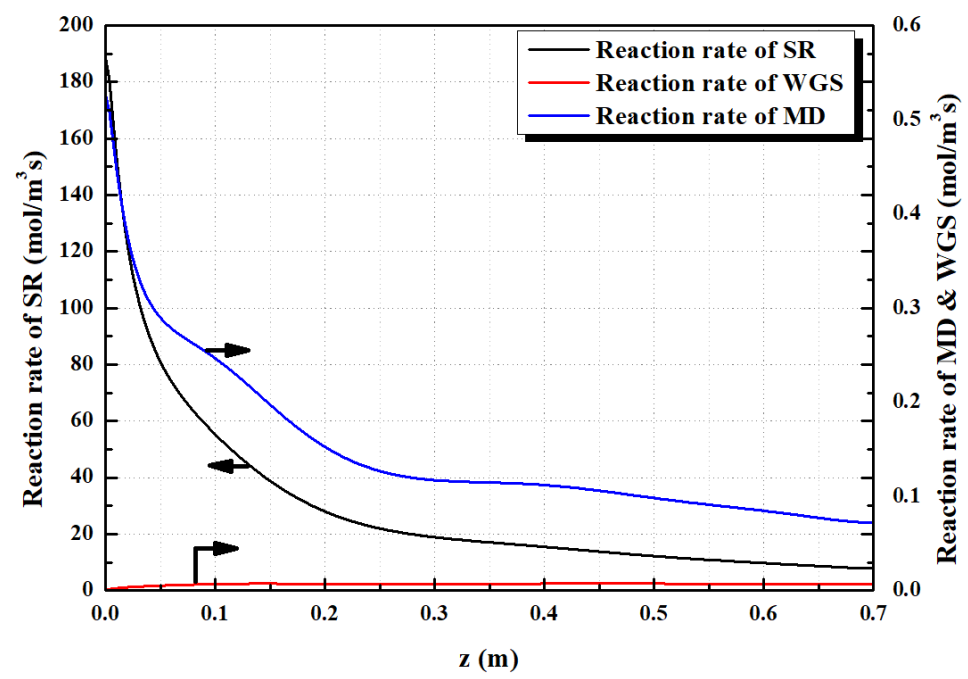

Figure 10. Contribution of elementary reaction kinetics along the tube. MD: methanol decomposition, SR: methanol steam reforming reaction, WGS: water gas shift. 
Because the steam reforming reaction mechanism dominates the overall reaction, the products are mostly $\mathrm{H}_{2}, \mathrm{CO}_{2}$, and $\mathrm{H}_{2} \mathrm{O}$. Figure 11 shows the mole fraction evolution of the product gases and the decay of methanol. As observed, the concentrations of $\mathrm{H}_{2}$ and $\mathrm{CO}_{2}$ gradually increase along the pipe. The maximum mole fraction of $\mathrm{H}_{2}$ is 0.58 , and $\mathrm{CH}_{3} \mathrm{OH}$ gradually decreases at the rear end of the reaction zone, resulting in a mole fraction of 0.09 . The mole fraction of the reactants $\mathrm{CH}_{3} \mathrm{OH}$ and $\mathrm{H}_{2} \mathrm{O}$ decreases as the reaction proceeds in the $\mathrm{Z}$ direction. Another aspect is the consumption rate of $\mathrm{H}_{2} \mathrm{O}$. As observed, the $\mathrm{H}_{2} \mathrm{O}$ concentration decreased over a short time in the frontal regime, and the concentration gradually decreased. Because the hydrogen production is dominated by steam reforming, it was observed that the consumption of water corresponded to the hydrogen concentration.

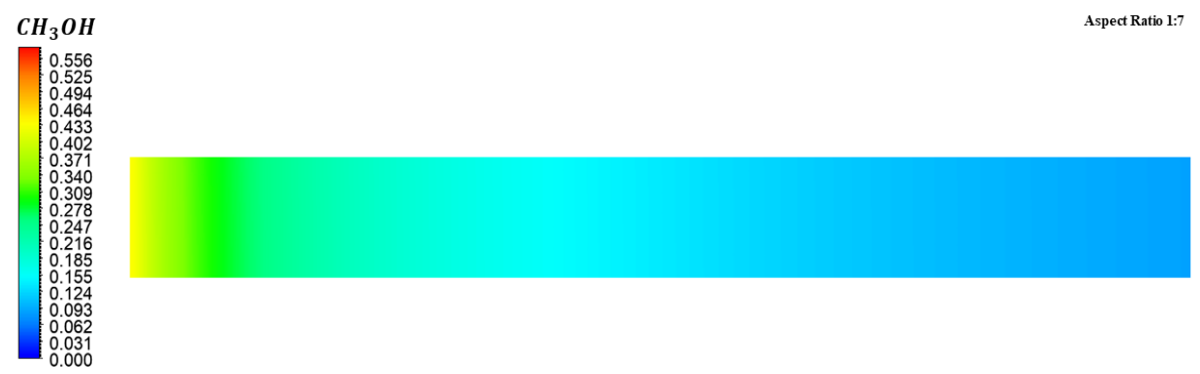

(a)
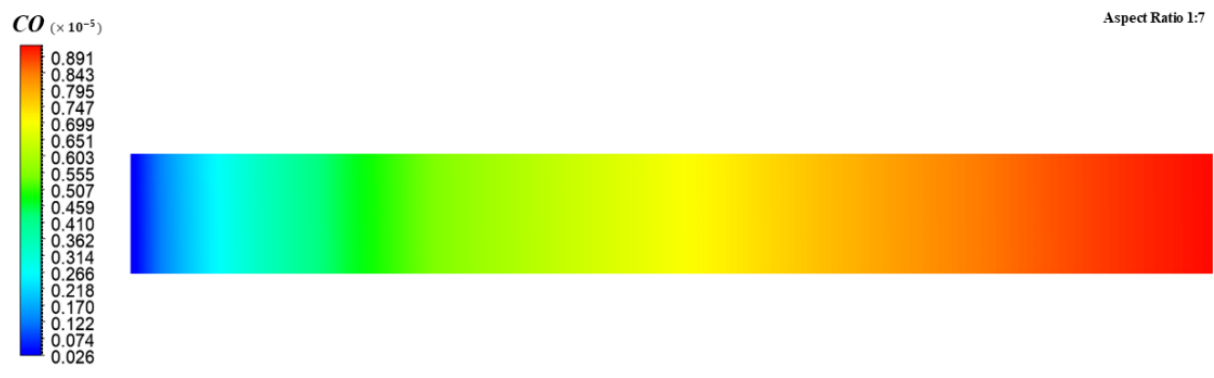

(b)

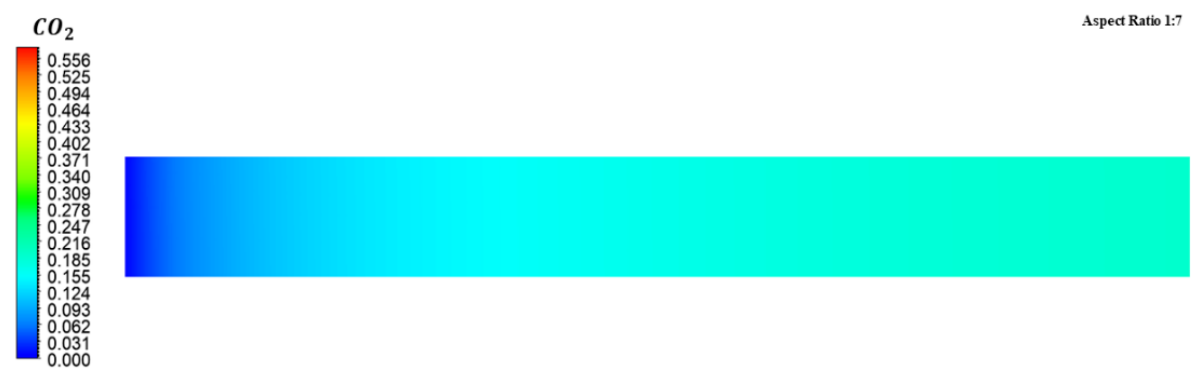

(c)



(d)

Figure 11. Cont. 


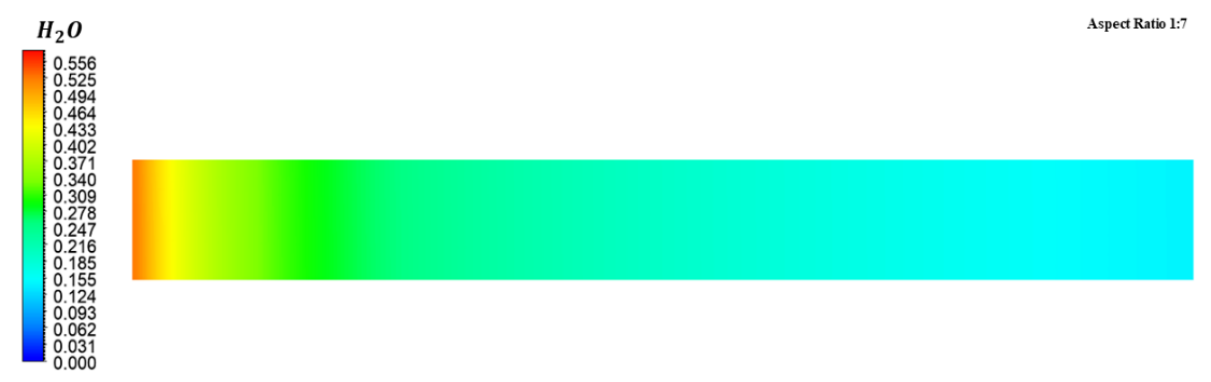

(e)

Figure 11. Species concentration of the methanol steam reforming reaction zone. (a) Mole fraction of $\mathrm{CH}_{3} \mathrm{OH}$, (b) Mole fraction of $\mathrm{CO}$, (c) Mole fraction of $\mathrm{CO}_{2}$, (d) Mole fraction of $\mathrm{H}_{2}$, (e) Mole fraction of $\mathrm{H}_{2} \mathrm{O}$.

\section{Conclusions}

In this study, computational analysis of high pressure methanol steam reforming reaction with the phase change of steam at saturation pressure are conducted.

(1) High-pressure methanol reforming reaction and high-pressure steam condensation phenomena are connected by constant heat flux conditions. Therefore, two different physical phenomena is explained by transferred heat flux.

(2) As the heat absorption of methanol steam reforming process results in vapor condensation, the inter-wall temperature between reforming zone and phase change zone is decreased.

(3) Since the temperature boundary layer is thinner than the liquid volume fraction boundary layer, the steam liquid mixture stays on the liquid water layer.

(4) The non-linear solid temperature of the inner wall affects the kinetics of the methanol decomposition reaction, but the kinetics of the steam reforming reaction and water gas shift reaction are rarely affected by the non-linear temperature profile of the inner wall.

(5) Since the overall reaction takes place within narrow radius porous media, the negligible concentration difference is observed through the steam reforming zone.

Author Contributions: Conceptualization, Y.K. and B.J.K.; Data curation, D.Y.; Formal analysis, H.J.; Writing —original draft, H.S.; Writing-review \& editing, S.Y. All authors have read and agreed to the published version of the manuscript.

Funding: This research was supported by a grant from the Agency for Defense Development (ADD) (grant number: UD180051GD).

Conflicts of Interest: The authors declare no conflict of interest.

\section{References}

1. Kim, S.; Yun, S.-W.; Lee, B.; Heo, J.; Kim, K.; Kim, Y.-T.; Lim, H. Steam reforming of methanol for ultra-pure $\mathrm{H} 2$ production in a membrane reactor: Techno-economic analysis. Int. J. Hydrogen Energy 2019, 44, 2330-2339. [CrossRef]

2. Iulianelli, A.; Ribeirinha, P.; Mendes, A.; Basile, A. Methanol Steam Reforming for hydrogen generation via conventional and membrane reactor: A review. Renew. Sustain. Energy Rev. 2014, 29, 355-368. [CrossRef]

3. Sahlin, S.L.; Andreasen, S.J.; Kær, S.K. System model development for a methanol reformed $5 \mathrm{~kW}$ high temperature PEM fuel cell system. Int. J. Hydrogen Energy 2015, 40, 13080-13089. [CrossRef]

4. Krummrich, S.; Llabrés, J. Methanol reformer-The next milestone for fuel cell powered submarines. Int. J. Hydrogen Energy 2015, 40, 5482-5486. [CrossRef]

5. Amphlett, J.C.; Evans, M.J.; Mann, R.F.; Weir, R.D. Hydrogen production by the catalytic steam reforming of methanol Part 2: Kinetics of methanol decomposition using girdler G66B catalyst. Can. J. Chem. Eng. 1985, 63, 605-611. [CrossRef] 
6. Chein, R.; Chen, Y.; Chung, J.N. Numerical study of methanol-steam reforming and methanol-air catalytic combustion in annulus reactors for hydrogen production. Appl. Energy 2013, 102, 1022-1034. [CrossRef]

7. Ataallah, S.; Javad, S. Modeling and 3D-simulation of hydrogen production via methanol steam reforming in copper-coated channels of a mini reformer. J. Power Sources 2017, 352, 64-76.

8. Shuji, F.; Hirotaka, K.; Takuya, K.; Mitsuyoshi, N.; Hiroyuki, W. Steam reforming behavior of methanol using paper-structured catalysts: Experimental and computational fluid dynamic analysis. Int. J. Hydrogen Energy 2008, 33, 1661-1670.

9. Ji, H.; Lee, J.; Choi, E.; Seo, I. Hydrogen Production from steam reforming using an indirect heating method. Int. J. Hydrogen Energy 2018, 43, 3655-3663. [CrossRef]

10. Ji, H.; Lee, J.; Choi, E.; Yang, S. Methanol Steam Reforming Using Multilayer Cup Structure for Catalyst Support. Trans. Korean Hydrog. New Energy Soc. 2020, 31, 202-209.

11. Ji, H.; Choi, E.; Lee, J. Optimal Operating Condition of Pressurized Methanol Fuel Processor for Underwater Environment. Trans. Korean Hydrog. New Energy Soc. 2016, 27, 485-493. [CrossRef]

12. Park, J.-E.; Park, J.-H.; Yim, S.-D.; Kim, C.-S.; Park, E.D. A comparative study of commercial catalysts for methanol steam reforming. Korean Chem. Eng. Res. 2005, 43, 344-351.

13. Seo, B.C.; Kim, M.C.; Kim, G.R. Methanol steam reforming reaction, 192. Korean Chem. Eng. Res 2017, 10, 438-445.

14. Purnama, H.; Ressler, T.; Jentoft, R.; Soerijanto, H.; Schlögl, R.; Schomäcker, R. CO formation/selectivity for steam reforming of methanol with a commercial CuO/ZnO/Al2O3 catalyst. Appl. Catal. 2004, 259, 83-94. [CrossRef]

15. Chiu, Y.-J.; Chiu, H.-C.; Hsieh, R.-H.; Jang, J.-H.; Jiang, B.-Y. Simulation of Hydrogen Production by Methanol Steam Reforming. Energy Proc. 2019, 156, 38-42. [CrossRef]

16. Choi, Y.; Stenger, H.G. Kinetics, simulation and optimization of methanol steam reformer for fuel cell applications. J. Power Sources 2005, 142, 81-91. [CrossRef]

17. Ribeirinha, P.; Boaventura, M.; Lopes, J.C.B.; Sousa, J.; Mendes, A. Study of Different Designs of Methanol Steam Reformers: Experiment and Modeling. Int. J. Hydrogen Energy 2014, 39, 19970-19981. [CrossRef]

18. Lee, W.H. ANSYS Fluent ${ }^{\circledR}$ Theory Guide 2019R1. Available online: www.ansys.com (accessed on 18 May 2020).

19. Incropera, F.P.; Lavine, A.S.; Bergman, T.L.; DeWitt, D.P. Principles of Heat and Mass Transfer, 7th ed.; John Wiley \& Sons, Inc.: Hoboken, NJ, USA, 2013.

(C) 2020 by the authors. Licensee MDPI, Basel, Switzerland. This article is an open access article distributed under the terms and conditions of the Creative Commons Attribution (CC BY) license (http://creativecommons.org/licenses/by/4.0/). 